\title{
Synthesis and characterization of PbTe micro/nanostructures through hydrothermal method by using a novel capping agent
}

\author{
SHAHLA AHMADIAN-FARD-FINI, MASOUD SALAVATI-NIASARI ${ }^{*},+,+\dagger$ \\ and FATEMEH MOHANDES ${ }^{\dagger}$ \\ Department of Chemistry, Payame Noor University, Tehran, P.O. Box 19395-3697, I.R. Iran \\ †Department of Inorganic Chemistry, Faculty of Chemistry, University of Kashan, Kashan, P.O. Box 87317-51167, \\ I.R. Iran \\ ${ }^{\dagger}$ Institute of Nano Science and Nano Technology, University of Kashan, Kashan, P.O. Box 87317-51167, I.R. Iran
}

MS received 30 March 2013; revised 12 August 2013

\begin{abstract}
For the first time, a Schiff base compound derived from 1,8-diamino-3,6-dioxaoctane and 2-hydroxybenzophenone marked as (2-HBP)-(DaDo) was synthesized, characterized and then used as capping agent for the preparation of PbTe micro/nanostructures. Besides the as-synthesized Schiff base compound, $\mathrm{Pb}\left(\mathrm{NO}_{3}\right)_{2}$ and Te powders were applied as lead and telluride precursors. In addition, effect of preparation parameters like reaction time and temperature in hydrothermal synthesis on the morphology of the final products was tested. The products were analysed with the aid of SEM, XRD, FT-IR and EDS. Based on the obtained results, it was found that pure cubic phased PbTe has been obtained by this method. According to SEM images, it was found that uniform PbTe micro/nanocubes have been obtained at $180{ }^{\circ} \mathrm{C}$ for $12 \mathrm{~h}$. On the other hand, by increasing the reaction temperature from 3 to $24 \mathrm{~h}$, the production of cubic-like shapes increased.
\end{abstract}

Keywords. Nanostructure; chalcogenide; lead telluride; Schiff base; hydrothermal.

\section{Introduction}

In the past decade, the preparation of low-dimensional materials such as nanorods, nanowires, nanobelts and nanoparticles have attracted much attention due to their unusual chemical and physical properties (Mohandes et al 2010; Esmaeili et al 2011; HosseinpourMashkani et al 2012). Synthesis of nano-sized lead telluride $(\mathrm{PbTe})$ as a member of chalcogenides family has attracted significant attention due to its small bandgap $(0.31 \mathrm{eV}$ at $300 \mathrm{~K})$ and larger Bohr excitation radius. $\mathrm{PbTe}$ nanostructures as semiconductors have been widely applied in many fields such as infrared detectors, photo resistance, lasers and thermoelectric materials $(\mathrm{Du}$ et al 2002; Shchennikov and Ovsyannikov 2003; Nair et al 2004; Zogg et al 2004; Harman et al 2006). Up to now, various methods have been explored to synthesize lead telluride nanostructures. Wan et al (2010) synthesized $\mathrm{PbTe}$ nanocubes in hydrazine saturated alkaline solution by using $\mathrm{Pb}\left(\mathrm{NO}_{3}\right)_{2}$ and Te powder. Sonochemical synthesis of nanocrystalline $\mathrm{PbTe}$ with $\mathrm{Pb}$ as impurity has been reported by $\mathrm{Li}$ et al (2003) after sonication for $8 \mathrm{~h}$ by using $\mathrm{Pb}\left(\mathrm{CH}_{3} \mathrm{COO}\right)_{2} \cdot 3 \mathrm{H}_{2} \mathrm{O}$ and $\mathrm{Te}$ powder. PbTe

\footnotetext{
*Author for correspondence (salavati@kashanu.ac.ir)
}

nanowires with an average diameter of about $30 \mathrm{~nm}$ were produced by a hydrothermal process at $180^{\circ} \mathrm{C}$ for $24 \mathrm{~h}$ using tellurium nanowires as templates and $\mathrm{Pb}\left(\mathrm{NO}_{3}\right)_{2}$ (Tai et al 2008). Flower-like $\mathrm{PbTe}$ nanostructures were synthesized using $\mathrm{Pb}\left(\mathrm{CH}_{3} \mathrm{COO}\right)_{2} \cdot 3 \mathrm{H}_{2} \mathrm{O}$ and $\mathrm{Na}_{2} \mathrm{TeO}_{3}$ as precursors under hydrothermal conditions at $240{ }^{\circ} \mathrm{C}$ for $24 \mathrm{~h}$ (Zhou et al 2012). The alkaline hydrothermal synthesis of $\mathrm{PbTe}$ nanosheets by using $\mathrm{Pb}\left(\mathrm{NO}_{3}\right)_{2}$, $\mathrm{Na}_{2} \mathrm{TeO}_{3}$ and $\mathrm{NaBH}_{4}$ as starting materials and different surfactants was introduced by Zhu et al (2010). Hierarchical superstructures of lead chalcogenides were prepared by microwave-assisted method with $\mathrm{Pb}\left(\mathrm{CH}_{3} \mathrm{COO}\right)_{2}$. $3 \mathrm{H}_{2} \mathrm{O}$ and Te powder in ethylene glycol (Cao et al 2007). Cubic-like nanostructures of $\mathrm{PbTe}$ have been obtained via solvothermal route at $150{ }^{\circ} \mathrm{C}$ for $12 \mathrm{~h}$ in various solvents including ethanol, acetone and $N, N^{\prime}$-dimethylformamide (DMF) (Zhu et al 2008).

It is well-known that the presence of capping agents during the formation of nanostructures has a great effect on the morphology of the final products. Therefore, much attention has been paid to the study of such supramolecular structures, which can act as both template and microreactor for the controlled growth of products and it has been proved to be an effective structure director to control the morphology of nanomaterials (Lisiecki et al 1996; Jeevanandam et al 2000). For example, sodium dodecylbenzene sulfonate (SDBS) (Zhu et al 2010), 
sodium dodecyl sulfate (SDS) (Soofivand et al 2012), polyvinylpyrrolidone (PVP) (Mohandes and SalavatiNiasari 2013), polyethylene glycol (PEG) (Zhang et al 2007) and cetyltrimethylammonium bromide (CTAB) (Esmaeili-Zare et al 2012) have been applied as current ionic and polymeric capping agents.

Here, a Schiff base compound derived from 1,8-diamino3,6-dioxaoctane and 2-hydroxybenzophenone marked as (2-HBP)-(DaDo) was synthesized, characterized and then used as capping agent for the synthesis of $\mathrm{PbTe}$ micro/ nanostructures. Lead nitrate, Te powder, $\mathrm{N}_{2} \mathrm{H}_{4} \cdot \mathrm{H}_{2} \mathrm{O}$ and $\mathrm{NaOH}$ as starting reagents and ethylene glycol as solvent were used in hydrothermal synthesis of $\mathrm{PbTe}$ micro/nanostructures. The as-produced $\mathrm{PbTe}$ micro/nanostructures were characterized with the aid of XRD, SEM, EDS and FT-IR.

\section{Experimental}

\subsection{Materials and characterization}

All the reagents for the synthesis of the capping agent and $\mathrm{PbTe}$ micro/nanostructures such as 1,8-diamino-3,6dioxaoctane, 2-hydroxybenzophenone, methanol, $\mathrm{Pb}\left(\mathrm{NO}_{3}\right)_{2}$, Te powder, ethylene glycol, hydrazine hydrate $\left(\mathrm{N}_{2} \mathrm{H}_{4}\right.$. $\mathrm{H}_{2} \mathrm{O}$ ) and $\mathrm{NaOH}$ were purchased from Merck company (pro-analysis) and used without further purification. The Fourier transform infrared spectra were performed using $\mathrm{KBr}$ pellets on FT-IR spectrometer (Magna-IR, 550 Nicolet) in the range of $400-4000 \mathrm{~cm}^{-1}$. The powder $\mathrm{X}$-ray diffraction (XRD) patterns were collected from a diffractometer of Philips company with X'PertPro monochromatized $\mathrm{CuK} \alpha$ radiation $(\lambda=1.54 \AA)$. A Cam Scan MV2300 scanning electron microscope (SEM) was used to investigate morphology of the products. The energy dispersive spectrometry (EDS) analysis was studied by XL30, Philips microscope. ${ }^{1} \mathrm{H}$ NMR spectrum of (2HBP)-(DaDo) was recorded by BRUKER (400 MHz) in $\mathrm{CDCl}_{3}$.

\subsection{Synthesis of Schiff base compound}

A typical procedure for the synthesis of (2-HBP)-(DaDo) compound is as follows: a solution containing $2 \mathrm{~mol}$ of 1,8-diamino-3,6-dioxaoctane in $50 \mathrm{~mL}$ of methanol was added dropwise into a solution involving 4 mol of 2hydroxybenzophenone in $50 \mathrm{~mL}$ of methanol. The mixture was refluxed at $70{ }^{\circ} \mathrm{C}$ under magnetic stirring for $12 \mathrm{~h}$ to produce a yellow precipitate. The obtained yellow precipitate was filtered and washed with methanol several times and finally dried at $50^{\circ} \mathrm{C}$ in vacuum for $12 \mathrm{~h}$. The chemical reaction for the preparation of (2-HBP)(DaDo) is seen in scheme 1. The as-obtained Schiff base compound was characterized by ${ }^{1} \mathrm{H} N M R$ and FT-IR.

\subsection{Synthesis of PbTe micro/nanostructures}

In a typical process, $2 \mathrm{mmol}$ of Te powder, $0.02 \mathrm{~g}$ of $\mathrm{NaOH}$ and $3 \mathrm{~mL}$ of $\mathrm{N}_{2} \mathrm{H}_{4} \cdot \mathrm{H}_{2} \mathrm{O}(85 \%)$ were dissolved in $30 \mathrm{~mL}$ of ethylene glycol under magnetic stirring. When the Te powder was completely dissolved, colour of the reaction became purple. Then $2 \mathrm{mmol}$ of $\mathrm{Pb}\left(\mathrm{NO}_{3}\right)_{2}$ plus $0 \cdot 3 \mathrm{~g}$ of the Schiff base dissolved in $30 \mathrm{~mL}$ of ethylene glycol was added into the above solution dropwise. The resultant mixture was put into a Teflon-lined stainless steel autoclave with a volume capacity of $100 \mathrm{~mL}$. The autoclave was then sealed and maintained at 160, 180 and $200{ }^{\circ} \mathrm{C}$ for $12 \mathrm{~h}$, respectively. Then, the container was cooled to room temperature naturally. The black precipitates obtained were collected, washed with methanol and distilled water several times and dried at $50{ }^{\circ} \mathrm{C}$ in vacuum for $12 \mathrm{~h}$. To investigate the effect of reaction time on the morphology of the products, the experiment was done at $180{ }^{\circ} \mathrm{C}$ for $3,6,9$ and $24 \mathrm{~h}$ in the same conditions, respectively. The preparation conditions have been illustrated in table 1. As shown in table 1, samples 1-7 were related to $\mathrm{PbTe}$ micro/nanostructures synthesized by hydrothermal method at different conditions. The products were characterized by XRD, SEM and EDS.

\section{Results and discussion}

\subsection{Characterization of Schiff base compound}

${ }^{1} \mathrm{H}$ NMR spectrum of the as-produced (2-HBP)-(DaDo) in the range of $0-20 \mathrm{ppm}$ is shown in figure $1(\mathrm{a}) .{ }^{1} \mathrm{H}$ NMR spectrum expanded in the range of 6.6-7.7 ppm attributed to the aromatic hydrogens are seen in the inset. ${ }^{1} \mathrm{H}$ NMR

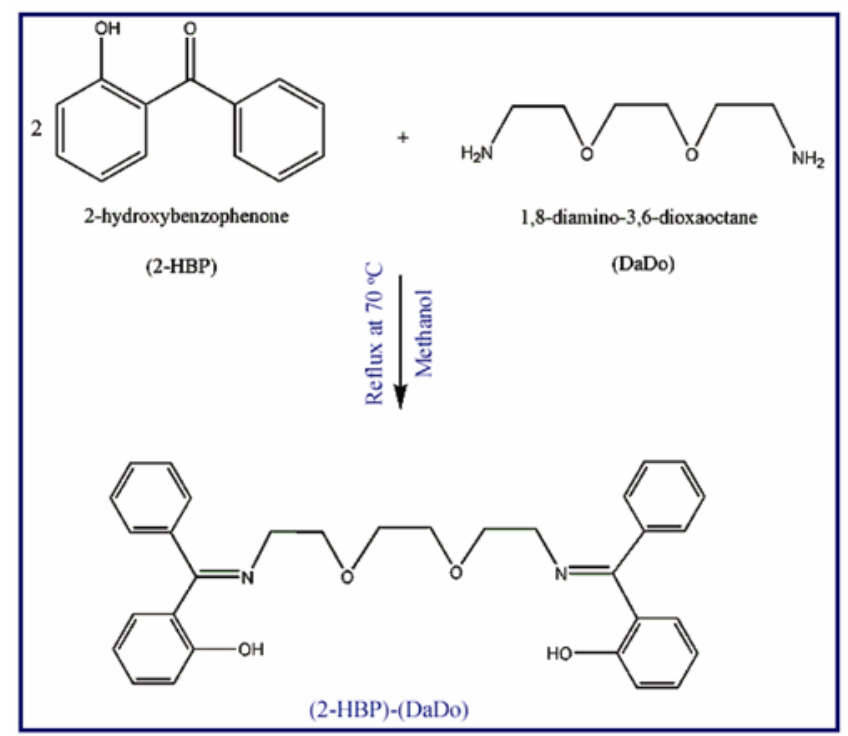

Scheme 1. Chemical reactions for preparation of as-used Schiff base. 
Table 1. Preparation conditions for synthesis of $\mathrm{PbTe}$ micro/nanostructures.

\begin{tabular}{lcrll}
\hline Sample & Temperature $\left({ }^{\circ} \mathrm{C}\right)$ & Time $(\mathrm{h})$ & Morphology & SEM image \\
\hline 1 & 160 & 12 & Irregular shapes including nanocubes & Figure 2(a) \\
2 & 180 & 12 & Micro/nanocubes & Figure 2(b) \\
3 & 200 & 12 & Nanoparticles & Figure 2(c) \\
4 & 180 & 3 & Irregular shapes including nanocubes, nanoparticles and nanorods & Figure 4(a) \\
5 & 180 & 6 & Agglomerated particles plus a small amount of nanocubes & Figure 4(b) \\
6 & 180 & 9 & Micro/nanocubes & Figure 4(c) \\
7 & 180 & 24 & Micro/nanocubes and small amount of nanorods & Figure 4(d) \\
\hline
\end{tabular}
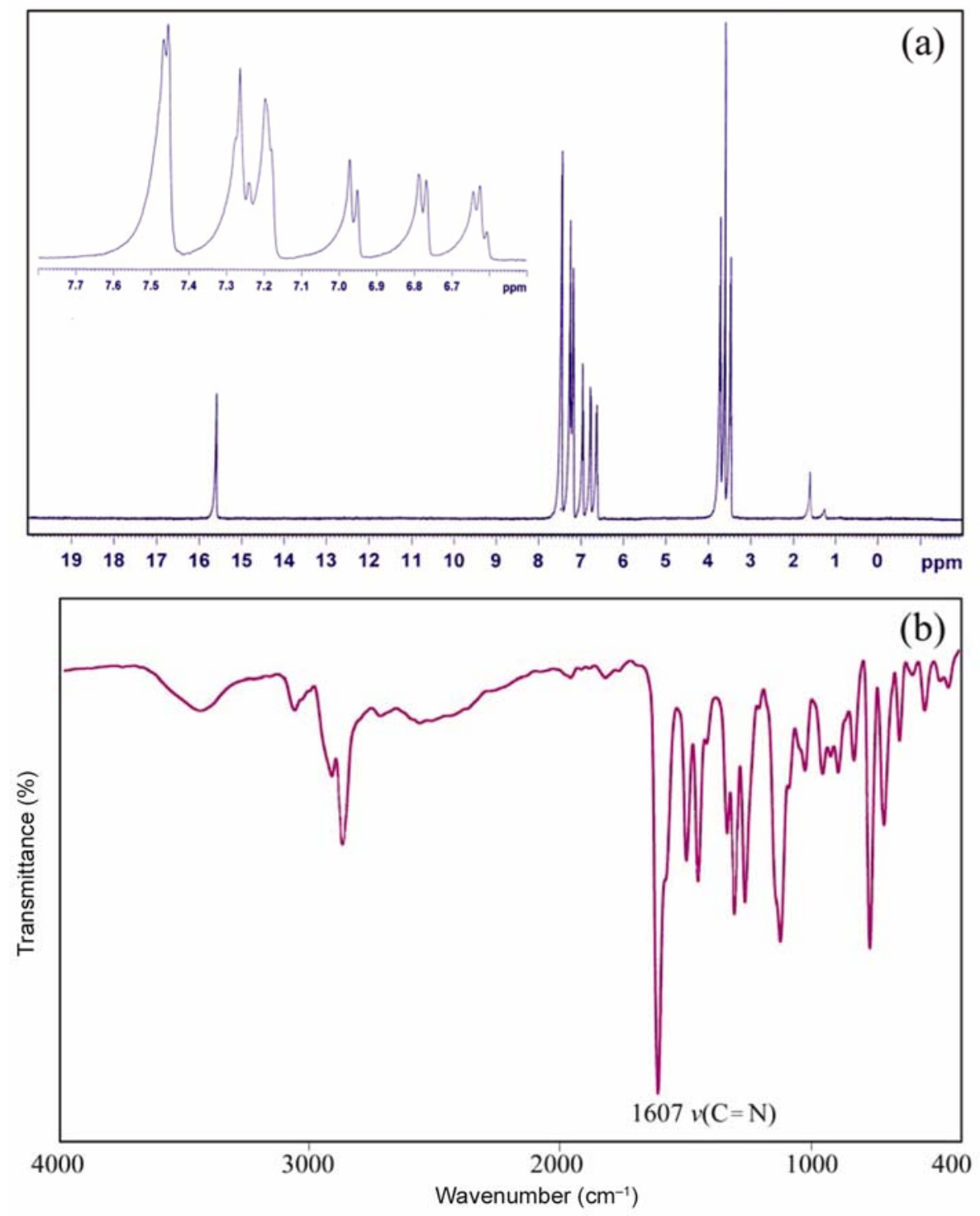

Figure 1. ${ }^{1} \mathrm{H}$ NMR (a) and FT-IR (b) spectra of as-synthesized Schiff base.

$\left(400 \mathrm{MHz}, \mathrm{CDCl}_{3}\right)$ data for this compound is as follows: $\delta$ : $15.65(s, 2 \mathrm{H}, \mathrm{OH}) ; 6.607-7.471(\mathrm{~m}, 18 \mathrm{H}$, aromatic); $3.469-3.739\left(t, s, 12 \mathrm{H},-\mathrm{CH}_{2}-\right)$. These results proved the formation of the Schiff base compound derived from 1,8diamino-3,6-dioxaoctane and 2-hydroxybenzophenone. FT-IR spectrum of the as-prepared (2-HBP)-(DaDo) was presented in figure 1(b). The strong peak marked at $1607 \mathrm{~cm}^{-1}$ is attributed to $v(\mathrm{C}=\mathrm{N})$ as a characteristic band for the Schiff base compound. The ring skeletal vibrations $(\mathrm{C}=\mathrm{C})$ of the Schiff base compound were observed at 1494 and $1448 \mathrm{~cm}^{-1}$. The phenolic $\mathrm{C}-\mathrm{O}$ stretching vibration appeared at $1258 \mathrm{~cm}^{-1}$ in this compound. All 

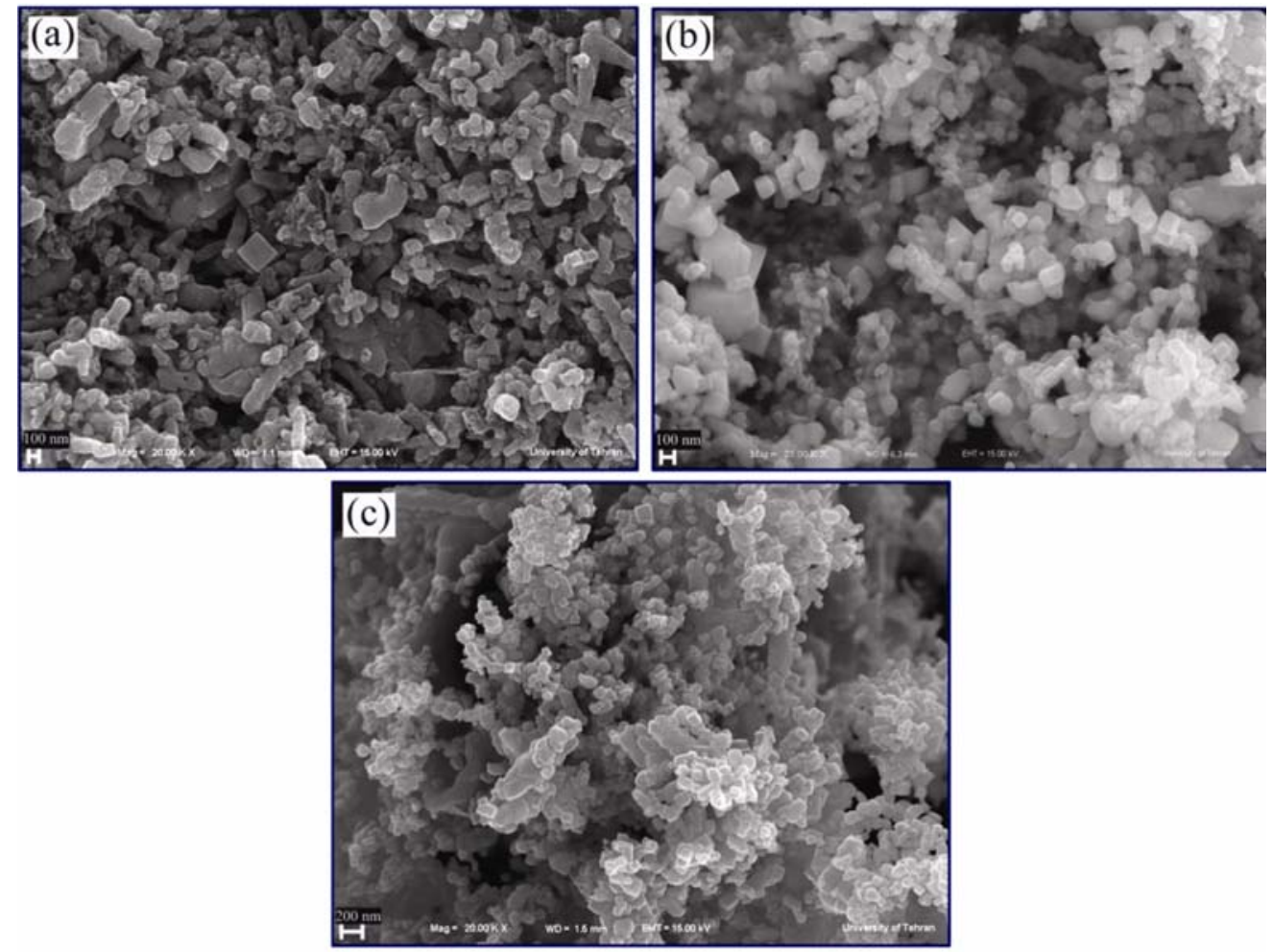

Figure 2. SEM images of products synthesized at 160 (a), 180 (b) and $200{ }^{\circ} \mathrm{C}$ (c) for $12 \mathrm{~h}$.

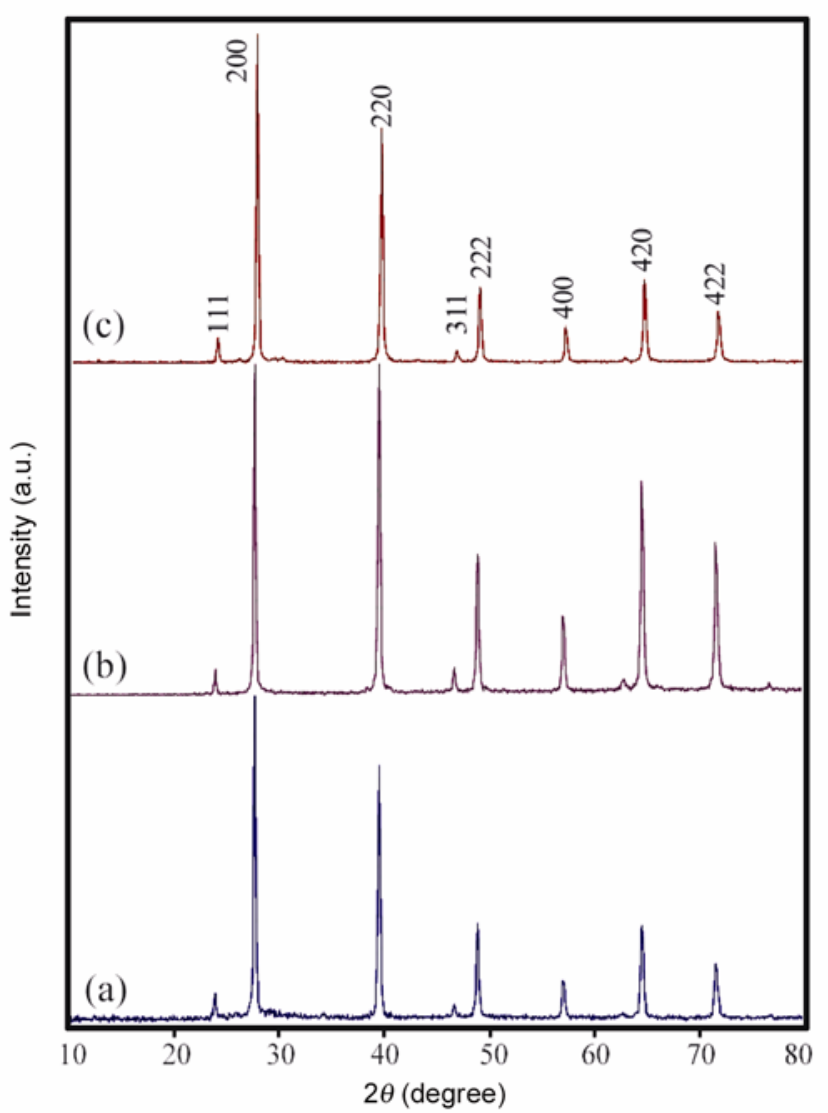

Figure 3. XRD patterns of products synthesized at 160 (a), 180 (b) and $200{ }^{\circ} \mathrm{C}(\mathbf{c})$ for $12 \mathrm{~h}$. the absorption bands in FT-IR spectrum of (2-HBP)(DaDo) were attributed to the Schiff base compounds (Kazemi-Babaheydari et al 2012). ${ }^{1} \mathrm{H}$ NMR and FT-IR spectra proved the formation and purity of the assynthesized Schiff base compound.

\subsection{Characterization of PbTe micro/nanostructures}

To investigate effect of temperature on the morphology of the final products, the starting reagents were heated at 160 (sample 1), 180 (sample 2) and $200{ }^{\circ} \mathrm{C}$ (sample 3) at the same conditions. SEM images of the samples 1-3 are seen in figures $2(\mathrm{a}-\mathrm{c})$, respectively. As shown in figure 2(a), morphology of the sample 1 consists of irregular shapes including a small amount of cubic-like micro/ nanostructures. By increasing the temperature from 160 to $180{ }^{\circ} \mathrm{C}$, the formation of cubic-like nanostructures was observed in SEM image of sample 2 (figure $2 \mathrm{~b}$ ). On further increasing the temperature to $200{ }^{\circ} \mathrm{C}$, particle-like nanostructures were obtained (figure 2(c)). Based on SEM images presented in figure 2, it was found that selfassembly of PbTe crystals to produce cubic-like micro/ nanostructures increased at $180^{\circ} \mathrm{C}$.

XRD patterns of the samples synthesized at 160,180 and $200{ }^{\circ} \mathrm{C}$ are shown in figures $3(\mathrm{a}-\mathrm{c})$, respectively. All the reflection peaks in figures $3(\mathrm{a}-\mathrm{c})$ can be indexed to the cubic PbTe with cell constants $a=b=c=6.4610 \AA$ (JCPDS card no. 77-0246). XRD results proved high crystallinity and purity of the products synthesized by 

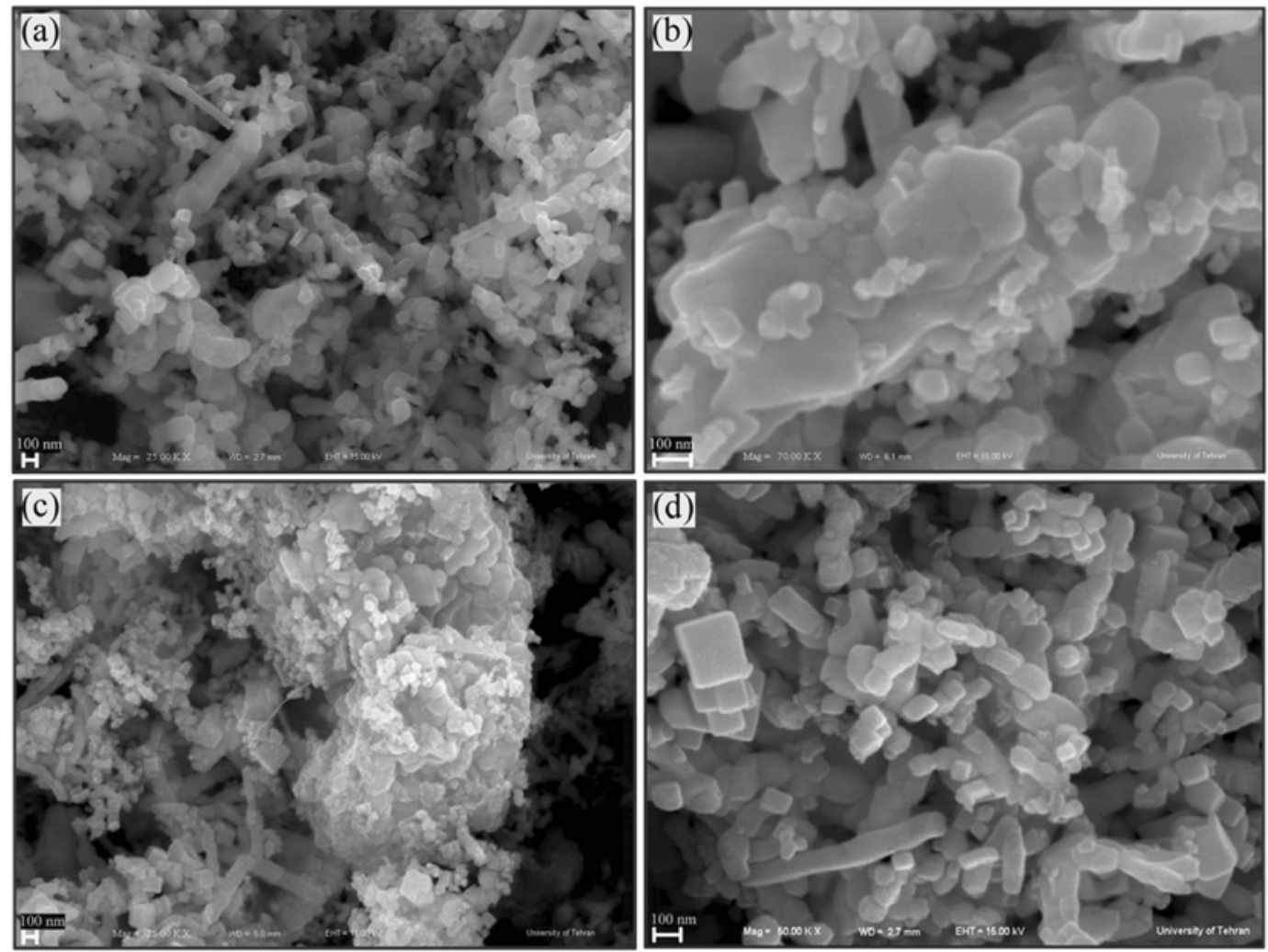

Figure 4. SEM images of products synthesized at $180^{\circ} \mathrm{C}$ after heating for 3 (a), 6 (b), 9 (c) and $24 \mathrm{~h}(\mathbf{d})$.

hydrothermal method. The crystalline size of the assynthesized products was calculated from the major diffraction peak (2 00$)$ using the Scherrer formula $\left(D_{\mathrm{c}}=K \lambda / \beta \cos \theta\right)$ (Jenkins and Snyder 1996). The crystal diameters of samples 1, 2 and 3 estimated by the DebyeScherrer formula were about 95,83 and $90 \mathrm{~nm}$, respectively.

To study effect of the reaction time on the morphology of the final products, experiment was carried out at $180^{\circ} \mathrm{C}$ for 3 (sample 4), 6 (sample 5), 9 (sample 6) and $24 \mathrm{~h}$ (sample 7) at the same conditions, respectively. SEM images of samples 4-7 are seen in figures $4(\mathrm{a}-\mathrm{d})$, respectively. When the reaction time was $3 \mathrm{~h}$, morphology of products was composed of rod-like, cubic-like and particle-like micro/nanostructures (figure 4a). When the reaction time was $6 \mathrm{~h}$, although the presence of nanorods disappeared, formation of the nanocubes is also seen in the morphology of sample 5 (figure $4 \mathrm{~b}$ ). In addition, agglomeration of the nanoparticles in sample 5 is very high. As shown in figure 4(c and d), the formation of cubic-like nanostructures are increased by increasing the reaction time to 9 and $24 \mathrm{~h}$. According to SEM image presented in figure 4(d), it is observed that rod-like nanostructures were produced by self-assembly of cubiclike nanostructures. Therefore, it can be found that by increasing the reaction time at the same conditions, the production of uniform nanocubes increased.
To further study the purity and chemical composition of the products, EDS spectrum of the sample 3 formed at $200{ }^{\circ} \mathrm{C}$ for $12 \mathrm{~h}$ was taken and shown in figure 5 . Figure 5 indicates that the elements in sample 3 are $\mathrm{Pb}$ and $\mathrm{Te}$ only ( $\mathrm{Si}$ signal was from the substrate). EDS results gave a rough atomic ratio of $\mathrm{Pb}: \mathrm{Te}$ as nearly $1: 1(\mathrm{~Pb}: 46 \cdot 84$; Te: 53.16), confirming purity of products synthesized through this route.

\subsection{Possible formation mechanism of PbTe micro/nanostructures}

Based on the available reports, it was found that $\mathrm{PbTe}$ can be formed by two independent pathways, involving ionic and atomic processes. It was found that in the ionic process, $\mathrm{Pb}^{2+}$ ions can react with $\mathrm{Te}^{2-}$ ions to generate $\mathrm{PbTe}$ nuclei. Besides, in the atomic process, the metal $\mathrm{Pb}$ reduced from $\mathrm{Pb}^{2+}$ by reducing agent and it combined with metal Te to generate $\mathrm{PbTe}$ nuclei (Zhu et al 2008; Wan et al 2009; Cao et al 2010). It must be remembered that the formation of $\mathrm{PbTe}$ through both ionic and atomic processes results from red-ox reactions. The main steps for the formation of $\mathrm{PbTe}$ nanostructures by hydrothermal method are as follows:

$$
3 \mathrm{Te}+6 \mathrm{OH}^{-} \rightarrow 2 \mathrm{Te}^{2-}+\mathrm{TeO}_{3}^{2-}+3 \mathrm{H}_{2} \mathrm{O},
$$




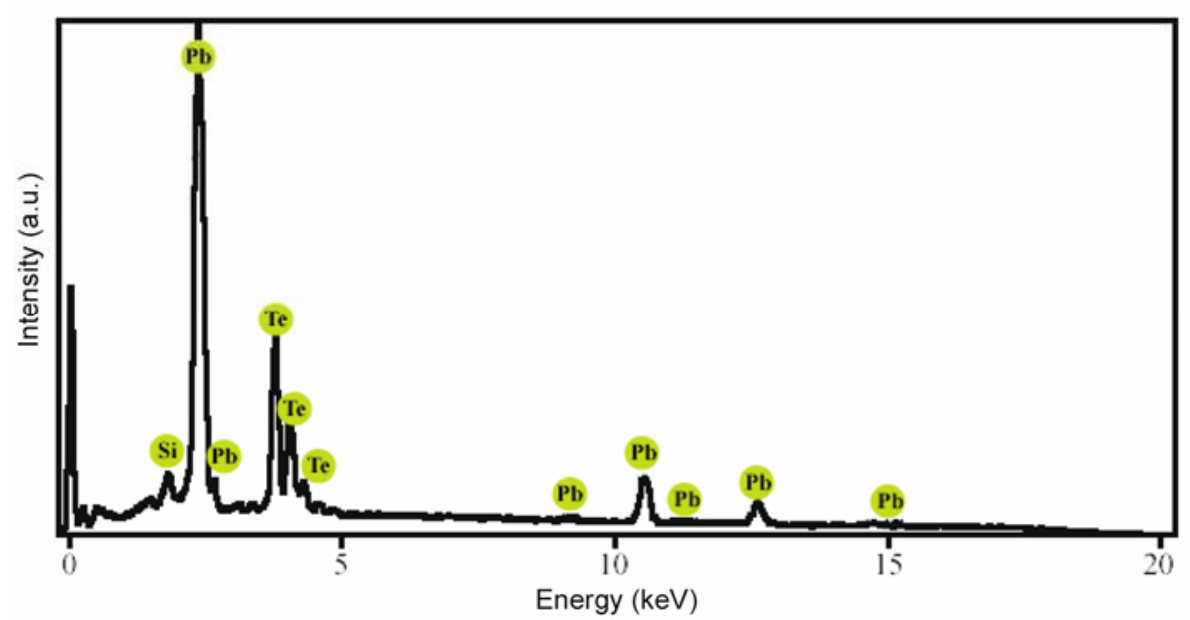

Figure 5. EDS spectrum of PbTe micro/nanostructures.

$$
\begin{aligned}
& \mathrm{TeO}_{3}^{2-}+\mathrm{N}_{2} \mathrm{H}_{4}+4 \mathrm{OH}^{-} \rightarrow \mathrm{Te}_{a+1}^{2-}+\mathrm{N}_{2}+4 \mathrm{H}_{2} \mathrm{O}, \\
& \mathrm{Te}_{a+1}^{2-} \rightarrow \mathrm{Te}+\mathrm{Te}^{2-}, \\
& \mathrm{N}_{2} \mathrm{H}_{4}+4 \mathrm{OH}^{-}+2 \mathrm{~Pb}^{2+} \rightarrow 2 \mathrm{~Pb}+\mathrm{N}_{2}+4 \mathrm{H}_{2} \mathrm{O}, \\
& \mathrm{Pb}^{2+}+\mathrm{Te}^{2-} \rightarrow \mathrm{PbTe}, \\
& \mathrm{Pb}+\mathrm{Te} \rightarrow \mathrm{PbTe} .
\end{aligned}
$$

According to the proposed formation mechanism of $\mathrm{PbTe}$, addition of $\mathrm{NaOH}$ accelerated the dissolution process of Te powder. The disproportional reaction of Te can produce $\mathrm{TeO}_{3}^{2-}$ ions, which can reduce to $\mathrm{Te}_{a+1}^{2-}$ ions by hydrazine hydrate. $\mathrm{Te}_{a+1}^{2-}$ ions with purple-black colour consist of $\mathrm{Te}$ and $\mathrm{Te}^{2-}$ ions (Lisiecki et al 1996). By reaction between $\mathrm{Te}^{2-}$ and $\mathrm{Pb}^{2+}$ ions, $\mathrm{PbTe}$ was formed via an ionic process $(1,2,3,5)$. In addition, Te powder can react with the metal $\mathrm{Pb}$ reduced from $\mathrm{Pb}^{2+}$ by hydrazine hydrate through an atomic process to produce $\mathrm{PbTe}$. Because of the presence of hydrazine hydrate as a reductant in the reaction vessel, the formation of $\mathrm{PbTe}$ nuclei through the atomic mechanism was possible $(3,4,6)$. When the presence of the metal $\mathrm{Pb}$ and $\mathrm{Te}$ was not observed in XRD patterns of the products, we could propose an atomic formation mechanism for the synthesis of $\mathrm{PbTe}$ nanostructures. In addition, the experimental observations such as the formation of the purple solution including $\mathrm{Te}^{2-}$ ions proved the ionic formation mechanism.

\section{Conclusions}

In summary, cubic-like $\mathrm{PbTe}$ micro/nanostructures were successfully fabricated by hydrothermal routes. A new Schiff base compound derived from 1,8-diamino-3,6dioxaoctane and 2-hydroxybenzophenone was synthesized and then used as capping agent instead of the current surfactant molecules for the preparation of $\mathrm{PbTe}$ nanostructures. Pure cubic phased $\mathrm{PbTe}$ nanostructures without any impurities like $\mathrm{Pb}$ and $\mathrm{Te}$ have been obtained by hydrothermal approach. It was found that by increasing reaction time from 3 to $24 \mathrm{~h}$, the formation of $\mathrm{PbTe}$ nanocubes increased. We hope that the synthesis and application of new Schiff base compounds for the preparation of nano-sized materials can be useful to control crystal growth and morphology of nanomaterials.

\section{Acknowledgement}

Authors are grateful to the council of University of Kashan for providing financial support to undertake this work.

\section{References}

Cao H, Gong Q, Qian X, Wang H, Zai J and Zhu Z 2007 Cryst. Growth Des. 7425

Cao Y Q, Zhu T J and Zhao X B 2010 J. Alloys Compd. 493 423

Du H, Chen C, Krishan R, Krauss T D, Harbold J M, Wise F W, Thomas M G and Silcox J 2002 Nano Lett. 21321

Esmaeili E, Salavati-Niasari M, Mohandes F, Davar F and Seyghalkar H 2011 Chem. Eng. J. 170278

Esmaeili-Zare M, Salavati-Niasari M and Sobhani A 2012 Ultrason. Sonochem. 191079

Harman T C, Reeder R E, Walsh M P, LaForge B E, Hoyt C D and Turner G W 2006 Appl. Phys. Lett. 88243504

Hosseinpour-Mashkani S M, Mohandes F, Salavati-Niasari M and Venkateswara Rao K 2012 Mater. Res. Bull. 47 3148

Jeevanandam P, Koltypin Y, Mastai Y and Gedanken A 2000 J. Mater. Chem. 102143

Jenkins R and Snyder R L 1996 in Chemical analysis: introduction to X-ray powder diffractometry (New York: John Wiley and Sons Inc.)

Kazemi-Babaheydari A, Salavti-Niasari $M$ and Khansari A 2012 Particuology 10759 
Li Q, Ding Y, Shao M, Wu J, Yu G and Qian Y 2003 Mater. Res. Bull. 38539

Lisiecki I, Billoudet F and Pileni M P 1996 J. Phys. Chem. 100 4160

Mohandes F, Davar F and Salavati-Niasari M 2010 J. Magn. Magn. Mater. 322872

Mohandes F and Salavati-Niasari M 2013 Ultrason. Sonochem. 20354

Nair P S, Friz K P and Scholes G 2004 Chem. Commun. 24 2084

Shchennikov V V and Ovsyannikov S V 2003 Solid State Commun. 126373

Soofivand F, Mohandes F and Salavati-Niasari M 2012 Micro Nano Lett. 7283
Tai G, Guo W and Zhang Z 2008 Cryst. Growth Des. 82906

Wan B, Hu C, Feng B, Xi Y and He X 2009 Mater. Sci. Eng. B163 57

Wan B, Hu C, Xi Y, Xu J and He X 2010 Solid State Sci. 12 123

Zhang D, Fu H, Shi L, Pan C, Li Q, Chu Y and Yu W 2007 Inorg. Chem. 462446

Zhou N, Chen G, Yang X and Zhang X 2012 J. Phys. Chem. Solids 73280

Zhu T J, Chen X, Meng X Y, Zhao X B and He J 2010 Cryst. Growth Des. 103727

Zhu T J, Liu Y Q and Zhao X B 2008 Mater. Res. Bull. 432850

Zogg H, Kellermann K, Alchalabi K and Zimin D 2004 Infrared Phys. Technol. 46155 